\title{
Assess Knowledge and Use of Body Mechanics Practices and its Association with Musculoskeletal Problems among Hospital Attendants in Selected Wards of PGIMER, Chandigarh
}

\author{
Priyanka $^{1}$, Kaur Ravneet ${ }^{1}$, Sakshi ${ }^{1}$, Sheetal ${ }^{1}$, Kaur Shubhreet ${ }^{1}$, Chozzin Tanzin ${ }^{1}$, \\ Bamania Suresh Kumar ${ }^{2}$, Kaur Damanpreet ${ }^{3}$ \\ ${ }^{1}$ B.Sc. Nursing 4th Year Students, NINE, PGIMER, Chandigarh. \\ ${ }^{2}$ Tutor, NINE, PGIMER, Chandigarh. \\ ${ }^{3}$ Tutor, NINE, PGIMER, Chandigarh \\ Corresponding Author: Kaur Ravneet
}

\begin{abstract}
Background: Work-related are more prone to get musculoskeletal problems due to excessive use of skeletal muscles while moving, lifting and transferring patients and heavy objects from one ward to different wards and thus, a result of a work related event and they are casually linked to physical load resulting from occupational activities such as high intensity forces, highly repetitive exertion, strong or long lasting muscular strains as well as environmental and psychological factors. There is lack of evidence of knowledge and practices of body mechanics in literature as compared to other health care workers.

Objectives: The study was planned to assess knowledge and use of body mechanics among hospital attendants and their association with the musculoskeletal problems among hospital attendants.

Methods: This descriptive study was conducted among hospital attendants working in tertiary care centre after taking permission from institute ethics committee and sanitation officer. Sample size of 174 was collected by convenience sampling technique from selected wards. Data was collected using Knowledge questionnaire, Interview schedule and Observation checklist and statistical analysis of the collected data was done by using SPSS version 22.0

Result: Study results depicted that $78.7 \%$ study subjects show poor knowledge score. $23.0 \%$ subjects follow good practices, $52.9 \%$ average practices and $24.1 \%$ poor practices. There was no statistically significant association was found among musculoskeletal problems and body mechanic practices of the subjects.

Conclusion: the study found that there is lack of knowledge and poor practices of body mechanics in majority of health attendants. However there is no statistically significant association is found between body mechanics practices and musculoskeletal problems among them. It will be helpful to develop and implement educational programme regarding body mechanics for hospital attendants to increase their efficiency and have healthy workforce.
\end{abstract}

Key Words: Body mechanics, Musculoskeletal problems, Hospital attendants, Practices, Knowledge

\section{INTRODUCTION}

Body mechanics is a term that involves coordinated movements of musculoskeletal and nervous system to maintain balance, posture, and body alignment that leads to the effective body functioning. Poor body mechanics increase the risk of injury to the body. Body mechanics also refers to the efficient use of body for making movements such as lifting heavy object or person, bending, stretching, 
sitting, standing or lying down for performing different task. ${ }^{[1]}$

Proper body mechanics is important for keeping good body posture. Body coordinates with muscles and nerves and maintain balance while lifting any object, bending or in standing position. Hospital attendant are group of workers that assist medical and nursing staff in routine activities and also involved in shifting, lifting and transferring of patient and heavy objects. Among hospital attendant the occupational hazards are work related stress, injury and lower back and they are prone to musculoskeletal problems. ${ }^{[2,3]}$

The occupational hazards during a work related event are casually linked to physical load resulting from occupational activities such as high intensity forces, highly repetitive exertion, strong or long lasting muscular strains as well as environmental and psychological factors.

A similar descriptive study was conducted by D'Souza P., Frank R. Mathias A. (2020) on knowledge and usage of body mechanics among class four IV workers. The result of study depicted that $64 \%$ of participants had poor knowledge, 34\% had average knowledge and only $2 \%$ had good knowledge of body mechanics and there was a weak positive correlation between knowledge and uses of body mechanics. ${ }^{[4]}$

Another study by Rawat A., Negi A., Rana M. et al (2017) on knowledge assessment on use of body mechanics and safety measures among ward attendants in selected hospitals, Dehradun, Uttarakhand revealed that majority of participants have average knowledge of body mechanics. Among all participants $79 \%$ was not suffering from back pain and rest $21 \%$ had back pain mainly due to the heavy lifting. ${ }^{[5]}$

The aim of present study was conducted to assess the body mechanics knowledge and practices among hospital attendants and their association with musculoskeletal problems among them.

\section{MATERIALS AND METHODS}

The study was conducted among hospital attendants of selected wards of PGIMER, Chandigarh after taking permission from Ethics Committee, NINE, PGIMER; Sanitation Officer, PGIMER. The accessible population was Hospital Attendants of selected wards who were available during data collection from $8 / 3 / 2021$ to $19 / 3 / 2021$. A sample size of 174 were included by Convenience sampling technique accordance with the inclusion criteria of Hospital Attendants who were able to understand Hindi/English/Punjabi language with age more than 18 years and work experience of more than six months. Written and informed consent was taken from the participants. Data collection was done using the self structured tool which consisted of four parts: - Sociodemographic profile, observation checklist, knowledge questionnaire, interview schedule to assess musculoskeletal problems. The participants were firstly observed for different activities being followed by them in their day to day routine which includes general activities ,turning the patient to one side of the bed ,transferring the patient from bed to wheelchair and vice versa, transferring patient from bed to stretcher and vice versa and moving, lifting and transferring heavy equipments(oxygen cylinder, trolley, heavy loads etc).for each correct step followed one mark was given and for the step not followed by the participants zero mark was given on observation checklist. Afterwards assessment of knowledge of the health attendants using knowledge questionnaire consisting of multiple choice questions and musculoskeletal problems they have been suffering were assessed by paper-pen mode.

\section{Statistical Analysis:}

Statistical analysis was done by using SPSS 22.0 using chi square test. $\mathrm{P}<0.005$ was considered to statistically significant. 
Priyanka et.al. Assess knowledge and use of body mechanics practices and its association with musculoskeletal problems among hospital attendants in selected wards of PGIMER, Chandigarh.

\section{RESULT}

Table 1: Socio-demographic profile of Hospital Attendants ( $N=174)$

\begin{tabular}{|c|c|c|}
\hline 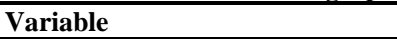 & $\mathrm{n}(\%)$ & \\
\hline $\begin{array}{l}\text { Age (years) } \\
<30\end{array}$ & $63(36.2)$ & Mean $\pm S D=35.7 \pm 9.789$ \\
\hline $31-40$ & $56(32.2)$ & Ranqe $=18-66$ vrs \\
\hline $41-50$ & $41(23.6)$ & \\
\hline$>50$ & $14(8)$ & \\
\hline Sex & & \\
\hline Male & $112(64.4)$ & \\
\hline Female & $62(35.6)$ & \\
\hline Educational Status & & \\
\hline Primary & $55(31.6)$ & \\
\hline Secondary & $87(50)$ & \\
\hline Graduate & $31(17.8)$ & \\
\hline Above Graduate & $1(0.6)$ & \\
\hline Area of habitat & & \\
\hline Rural & $48(27.6)$ & \\
\hline Semi-urban & $84(48.3)$ & \\
\hline Urban & $42(24.1)$ & \\
\hline Religion & & \\
\hline Hindu & $149(85.6)$ & \\
\hline Sikh & $22(12.6)$ & \\
\hline Muslim & $1(0.6)$ & \\
\hline Christian & $2(1.1)$ & \\
\hline Marital Status & & \\
\hline Married & $138(79.3)$ & \\
\hline Unmarried & $30(17.2)$ & \\
\hline Divorced & $1(0.6)$ & \\
\hline Widow & $5(2.9)$ & \\
\hline Type of Family & & \\
\hline Nuclear & $113(64.9)$ & \\
\hline Joint & $61(35.1)$ & \\
\hline Per capita income per month(Rs)* & & Meant \\
\hline $\begin{array}{l}<1129 \\
1130-2259\end{array}$ & $\begin{array}{l}1(0.6) . \\
19(10.9)\end{array}$ & $S D=6318.73 \pm$ \\
\hline $2260-3765$ & $56(32.2)$ & 8637.57Rs \\
\hline $3766-7532$ & $60(34.5)$ & Range $=1000-$ \\
\hline$>7533$ & $38(21.8)$ & \\
\hline
\end{tabular}

Table 1 depicts the sociodemographic profile of study subjects. Out of 174 study subjects two third $(68.4 \%)$ were in the age group $<40$. Majority $(64.4 \%)$ of the subjects were males. Half of the subjects $(50 \%)$ had secondary level of education whereas almost half $(48.3 \%)$ subjects were from urban background. Most of them $(85.6 \%)$ belong to Hindu religion, maximum $79.3 \%$ were married and $64.9 \%$ subjects belong to nuclear families. More than two third $(70.2 \%)$ subjects had work experience of less than 10 years as Hospital Attendents in PGIMER.

Table 1(A) Health Profile of Hospital Attendants. ( $N=174)$

\begin{tabular}{|l|l|l|}
\hline Variable & $\mathbf{n}(\%)$ & \\
\hline BMI $\left[\left(\mathrm{Kg} / \mathrm{m}^{2}\right)\right.$ Acc. to WHO classification & & Mean $\pm \mathrm{SD}=$ \\
$<18.5$ (underweight) & $18(10.3)$ & $24.36 \pm 3.662$ \\
$18.5-22.9$ (normal weight) & $93(53.4)$ & \\
23-24.9 (overweight) & $46(26.8)$ & \\
$>30$ (obese) & $17(9.8)$ & \\
\hline *BP(mm Hg) Acc. to AHA Classification & & \\
Normotensive (120/80 mmhg) & $162(93.1)$ & \\
Hypertensive (>140/90 mmhg) & $7(4)$ & \\
Hypotensive (<90/60 mmh) & $5(2.9)$ & \\
\hline *History of any surgery & $23(13.2)$ & \\
Yes & $19(10.9)$ & \\
\hline *Any Supplement /Medicine intake & \\
Yes(calcium/vitamin D/ multivitamins) & $19(10.9)$ & \\
\hline *Any diagnosed condition & $6(3.4)$ & \\
Yes & & \\
\hline Self reported illness & & \\
Yes & *Self reported & \\
\hline
\end{tabular}


Table 1(A) depicts health profile of hospital attendants. Half $(53.4 \%)$ of the subjects had normal weight whereas most (93.1\%) of the subjects were Normotensive. Only $(13.2 \%)$ of them had history of any surgery. Only $10.9 \%$ of the subjects had supplement/medicine intake and had history of any diagnosed condition .Only $3.4 \%$ of the subjects complaints self reported illness.

Table 2: Work experience of Hospital Attendants working in PGIMER, Chandigarh. $\mathrm{N}=174$

\begin{tabular}{|l|l|}
\hline Work experience in years & $\mathbf{n}(\%)$ \\
\hline$\leq 10$ & $(70.1)$ \\
\hline $11-15$ & $(15.5)$ \\
\hline $16-20$ & $(9.2)$ \\
\hline $21-25$ & $(2.9)$ \\
\hline$\leq 26$ & $(2.3)$ \\
\hline
\end{tabular}

Table 1: depicts work experience of hospital attendants working in PGIMER, Chandigarh. More than half of the subjects had work experience of $\leq 10 y e a r s .15 .25 \%$ of the subjects had work experience of 11-
15 years and only $2.30 \%$ of the subjects had work experience of $>26 y$ year
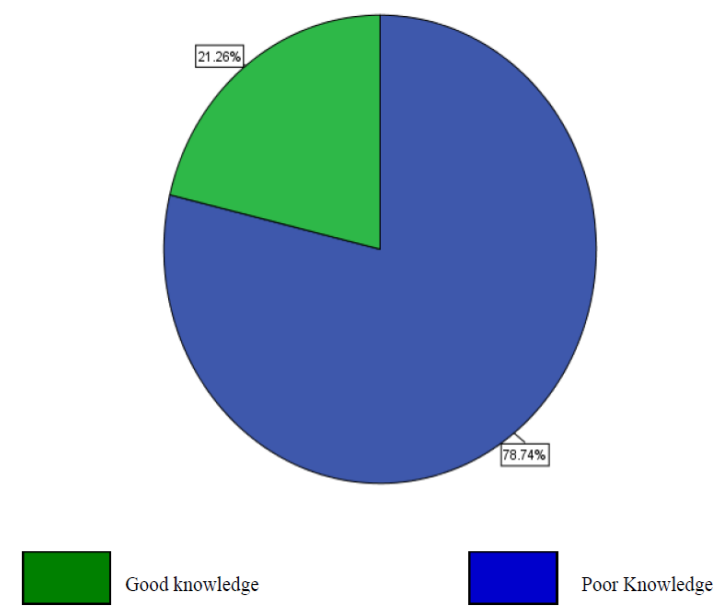

Figure2: Knowledge of body mechanics among hospital attendants

Figure 2: Shows $78.74 \%$ of the study subjects had poor knowledge, $21.26 \%$ had good knowledge regarding body mechanics.

Table2: Self reported musculoskeletal problems among hospital attendents, $N=174$

\begin{tabular}{|l|l|l|l|l|l|}
\hline Statement & Always & Very Often & Sometimes & Rarely & Never \\
\hline Experience of pain, Ache, discomfort during last month & $13(7.5)$ & $13(7.5)$ & $18(10.3)$ & $35(29.4)$ & $51(42.9)$ \\
\hline Back pain & $9(5.2)$ & $20(11.5)$ & $15(8.6)$ & $45(37.8)$ & $47(39.5)$ \\
\hline Knee pain & $9(5.2)$ & $3(1.7)$ & $15(8.6)$ & $28(23.5)$ & $76(63.9)$ \\
\hline Shoulder pain & $7(4.0)$ & $6(3.4)$ & $5(2.9)$ & $24(20.2)$ & $85(71.4)$ \\
\hline Neck pain & $5(2.9)$ & $6(3.4)$ & $3(1.7)$ & $22(18.5)$ & $89(74.8)$ \\
\hline Pain after work & $6(3.4)$ & $14(8.0)$ & $29(16.7)$ & $42(35.3)$ & $42(35.3)$ \\
\hline Interference of pain with working ability & $2(1.1)$ & $8(4.6)$ & $32(18.4)$ & $31(26.1)$ & $59(49.6)$ \\
\hline Injury, fall, accident while work & $0(0)$ & $0(0)$ & $14(8.0)$ & $32(26.9)$ & $77(64.7)$ \\
\hline
\end{tabular}

Table 2: depicts the response of hospital attendants for musculoskeletal problems. $7.5 \%$ of the study subjects had always and very often experience of pain, ache, discomfort during the last month. $11.5 \%$ had very often complaints of back pain, $8.6 \%$ had sometimes experience of knee pain. Only $4.0 \%$ of the study subjects had experience of shoulder pain and $2.9 \%$ had experienced neck pain. $16.7 \%$ of the study subjects had sometimes experienced pain after work and $18.4 \%$ of them felt sometimes interference of pain with their working ability.

Table 3: Practice scores of observation checklist of hospital attendants in different activities.

\begin{tabular}{|c|l|l|l|l|l|}
\hline & Statement & N & Good practice & Average practice & Poor practice \\
\hline 1. & General Activities & 174 & $40(23.0)$ & $92(52.9)$ & $42(24.1)$ \\
\hline 2. & $\begin{array}{l}\text { Moving, lifting and transferring heavy equipments (oxygen } \\
\text { cylinder, trolley, heavy loads etc) }\end{array}$ & 61 & $3(1.7)$ & $40(23.0)$ & $18(10.3)$ \\
\hline 3. & Transferring patient from stretcher to bed and vice versa. & 77 & $13(7.4)$ & $54(31.0)$ & $37(21.3)$ \\
\hline 4. & Transferring Patient from wheelchair to bed and vice versa. & 31 & $6(6.4)$ & $25(14.3)$ & $31(17.8)$ \\
\hline
\end{tabular}

Table 3:depicts body mechanics practices for different activities that were categorized into three categories based upon the score, for good practice (43-53), average practice(27-43), poor practice $(<27)$. showing that subjects performance for general activities was average (52.9\%), for moving lifting and transferring heavy equipments was average (23.0\%), for transferring patients from stretcher to bed and vice versa was also average $(31.0 \%)$ 
Priyanka et.al. Assess knowledge and use of body mechanics practices and its association with musculoskeletal problems among hospital attendants in selected wards of PGIMER, Chandigarh.

and for transferring patient from wheelchair

to bed and vice versa was poor(17.8\%).

Table 4: Association of Musculoskeletal problems and body mechanics practices among hospital attendants. $N=174$

\begin{tabular}{|c|c|c|c|c|c|c|c|}
\hline Statement & Practices & Always & $\begin{array}{l}\text { Very } \\
\text { often }\end{array}$ & Sometimes & Rarely & Never & $($ df,$p$ value $)=x^{2} / F$ \\
\hline \multirow{3}{*}{$\begin{array}{l}\text { Experience of pain, } \\
\text { Ache, discomfort during last month }\end{array}$} & Good & $1(3.6)$ & $1(3.6)$ & $4(14.3)$ & $6(21.4)$ & $16(57.1)$ & \multirow{3}{*}{$(8,0.151)=.616^{\mathrm{F}}$} \\
\hline & Average & $7(7)$ & 11(11) & $10(10)$ & $27(27)$ & $45(45)$ & \\
\hline & Poor & $5(10.9)$ & $1(2.2)$ & $4(8.7)$ & $20(43.5)$ & $16(34.8)$ & \\
\hline \multirow[t]{3}{*}{ Back pain } & Good & $1(3.6)$ & $2(7.1)$ & $3(10.7)$ & $10(35.7)$ & $12(42.9)$ & \multirow[t]{3}{*}{$(8,0.41)=7.769^{F}$} \\
\hline & Average & $5(5)$ & $16(16)$ & $6(6)$ & $30(30)$ & $43(43)$ & \\
\hline & Poor & $3(6.5)$ & $2(4.3)$ & $6(13)$ & $18(39.1)$ & $17(37)$ & \\
\hline \multirow[t]{3}{*}{ Knee pain } & Good & $2(7.1)$ & $1(3.6)$ & $5(17.9)$ & $5(17.9)$ & $15(53.6)$ & \multirow{3}{*}{$(8,0.71)=6.191^{\mathrm{F}}$} \\
\hline & Average & $6(6)$ & $1(1)$ & $8(8)$ & $25(25)$ & $60(60)$ & \\
\hline & Poor & $1(2.2)$ & $1+++(2.2)$ & $3(6.5)$ & $12(26.1)$ & $29(63)$ & \\
\hline \multirow[t]{3}{*}{ Shoulder pain } & Good & $1(3.6)$ & $1(3.6)$ & $2(7.1)$ & $3(10.7)$ & $21(75)$ & \multirow[t]{3}{*}{$(8,0.54)=6.255^{\mathrm{F}}$} \\
\hline & Average & $4(4)$ & $3(3)$ & $3(3)$ & $17(17)$ & $73(73)$ & \\
\hline & Poor & $2(4.3)$ & $2(4.3)$ & $0(0)$ & $12(26.1)$ & $30(65.2)$ & \\
\hline \multirow[t]{3}{*}{ Neck pain } & Good & $0(0)$ & $1(3.6)$ & $2(7.1)$ & $4(14.3)$ & $21(75)$ & \multirow{3}{*}{$(8,0.46)=6.142^{\mathrm{F}}$} \\
\hline & Average & $3(3)$ & $4(4)$ & $1(1)$ & $16(16)$ & $76(76)$ & \\
\hline & Poor & $2(4.3)$ & $1(2.2)$ & $0(0)$ & $10(21.7)$ & $33(71.7)$ & \\
\hline \multirow[t]{3}{*}{ Pain after work } & Good & $1(3.6)$ & $3(10.7)$ & $7(25)$ & $8(28.6)$ & $9(32.1)$ & \multirow[t]{3}{*}{$(8,0.87)=4.508^{F}$} \\
\hline & Average & $4(4)$ & $9(9)$ & $13(13)$ & $39(39)$ & $35(35)$ & \\
\hline & Poor & $1(2.2)$ & $2(4.3)$ & 8917.4) & $18(39.1)$ & 17(37) & \\
\hline \multirow[t]{3}{*}{ Interference of pain with working ability } & Good & $0(0)$ & $2(7.1)$ & $7(25)$ & $6(21.4)$ & $13(46.4)$ & \multirow[t]{3}{*}{$(10,0.81)=6.179^{\mathrm{F}}$} \\
\hline & Average & $1(1)$ & $5(5)$ & 19(19) & $21(21)$ & $53(53)$ & \\
\hline & Poor & $1(2.2)$ & $1(2.2)$ & $6(13)$ & $14(30.4)$ & $24(52.2)$ & \\
\hline \multirow{3}{*}{$\begin{array}{l}\text { Medical leave due to pain, ache } \\
\text { discomfort in muscles and bones }\end{array}$} & Good & $0(0)$ & $1(3.6)$ & $2(7.1)$ & $3(10.7)$ & $22(78.6)$ & \multirow[t]{3}{*}{$(8,0.23)=7.806^{\mathrm{F}}$} \\
\hline & Average & $1(1)$ & $6(6)$ & $6(6)$ & $23(23)$ & 64(64) & \\
\hline & Poor & $2(4.3)$ & $0(0)$ & $2(4.3)$ & $12(26.1)$ & $30(65.2)$ & \\
\hline \multirow[t]{3}{*}{ Injury, fall, accident while work } & Good & $0(0)$ & $0(0)$ & $2(7.1)$ & $9(32.1)$ & $17(60.7)$ & \multirow[t]{3}{*}{$(8,0.37)=6.590^{\mathrm{F}}$} \\
\hline & Average & $0(0)$ & $3(3)$ & $4(4)$ & $24(24)$ & 69(69) & \\
\hline & Poor & $2(4.3)$ & $1(2.2)$ & $1(2.2)$ & 11(23.9) & $31(67.4)$ & \\
\hline
\end{tabular}

Table 4: Depicts the association of musculoskeletal problems and body mechanics practices with the application of Chi-square test and Fischer exact test over 174 samples. Result depicts that there was no statistically significant association was found among musculoskeletal problems and body mechanics practices of the study subjects.

\section{DISCUSSION}

In present study, $36.2 \%$ of the study subjects were in the age group of $<30 \mathrm{yrs}$ with the mean age of 35.7 years with majority $(64.4 \%)$ were males \& two third $(70.1 \%)$ of the hospital attendants had work experience of less than 10 years. Similarly in Rawat A. et al (2017) study, half of them (53\%) belongs to age group 21-30 yrs with $79 \%$ of them were males and majority of them $(74 \%)$ had work experience of $7 \mathrm{yrs}^{[7]}$ while D'souza P. et al(2020) study, nearly half of them are between age group of 36-45 yrs with $74 \%$ of them were females and $41 \%$ had work experience of 6-10 yrs. ${ }^{[4]}$

The present study results showed that Based on the knowledge score, $78.7 \%$ of the study subjects had poor knowledge \& the rest $21.5 \%$ had good knowledge. Similar results were shown in study conducted by D'souza P. et al in $2020(\mathrm{~N}=100)$ in which $64 \%$ had poor knowledge and only $2 \%$ of them had good knowledge. ${ }^{[4]}$ In another similar study conducted by Afzal M, Gilani SA, Waqas A et al. in $2017(\mathrm{~N}=216)$ at Punjab Institute of Cardiology, Lahore revealed that $65 \%$ participants were having good knowledge and $15 \%$ were having no knowledge. ${ }^{[6]}$ In contrast to this, in a study conducted by Vidya VP, Freeda D, Dennis $\mathrm{S}$, et al. in $2014(\mathrm{~N}=100)$ on knowledge and practices of body mechanics among staff nurses at Mangalore concluded that 50\% subjects had good knowledge, $40 \%$ had very good knowledge and $10 \%$ had average knowledge. ${ }^{[7]}$ In another study conducted by Alzal A., Kowar R., Weqas A. et al in 2017 $(\mathrm{N}=150)$ on knowledge and practices of body mechanics technique among nurses at Lahore revealed among participant staff nurses, 65\% had fair knowledge and 35\% had poor knowledge of body mechanics. ${ }^{[6]}$ Thus it is indicated that the knowledge of hospital attendants and class four workers 
are poor as compared to nurses as per above quoted studies.

Regarding body mechanics practices, the subjects performance in general activities was average $(52.9 \%)$, for moving lifting and transferring heavy equipments was average $(23.0 \%)$, for transferring patients from stretcher to bed and vice versa was also average $(31.0 \%)$ and for transferring patient from wheelchair to bed and vice versa was poor(17.8\%).In a similar study by D'souza P. et al in 2020, the $74 \%$ of class IV workers poorly used body mechanics at workplace while rest $26 \%$ were using proper techniques. ${ }^{[4]}$ On contrary in a descriptive study conducted by Jayakrishan K. in $2016 \quad(\mathrm{~N}=100)$ on Knowledge and practice among staff nurses regarding body mechanics at Odisha revealed that $11 \%$ had excellent, $71 \%$ had moderate and $18 \%$ had mild extent of use of body mechanics practices. ${ }^{[8]}$ Another study was conducted by Karahan A, Bayraktar N, et al in 2004 in department of nursing among Turkish hospital workers including nurses experiencing low back pain because of heavy work activities like bending, twisting and frequent heavy lifting. Majority of the nurse used the body mechanics correctly while sitting (53.6\%), standing $(53.7 \%)$, carrying $(64.3 \%)$, pulling or pushing $(79.4 \%)$ moving the patient to a standing position(66.6\%). $57.1 \%$ of the nurses lifted and extended incorrectly and experienced low back pain ${ }^{[9]}$

The present study statistics shows that $7.5 \%$ of the study subjects had always and very often experience of pain, ache, discomfort during the last month. $11.5 \%$ had very often complaints of back pain, $8.6 \%$ had sometimes experience of knee pain. Only $4.0 \%$ of the study subjects had experience of shoulder pain and $2.9 \%$ had experienced neck pain.16.7\% of the study subjects has experienced pain after work and $18.4 \%$ of them find interference of pain with their working ability. Similar results are shown in the cross-sectional study conducted by Rawat A., Negi A., Rana M. et al (2017) on knowledge assessments on use of body mechanics and safety measures among ward attendants in selected hospitals, Dehradun, Uttarakhand revealed that $79 \%$ was not suffering from back pain; rest $21 \%$ has back pain mainly due to the heavy lifting. ${ }^{[5]}$

In a similar cross sectional study conducted by Tariah $\mathrm{H}$, Nafai S , Alajmi M et al in 2020 $(\mathrm{N}=94)$ on work related musculoskeletal disorders in nurses working in kingdom of Saudi Arabia and exploring the role of occupational therapist in increasing awareness and prevention of WRMDs among nurses. Most of nurses $(63.8 \%)$ indicated that they experienced discomfort during last 12 months in lower back followed by shoulders $50 \%$ and upper back $48.9 \%$. $25.5 \%$ of participants who indicated experiencing low back discomfort also indicated reduced work activity. ${ }^{[10]}$

In the present study it was indicated that there was no statistically significant relation between knowledge of body mechanics and body mechanics practices. Also no statistically significant relation between the body mechanics practices \& self reported musculoskeletal problems. Similarly in study conducted by Rawat A., Negi A., Rana M. et al (2017) on ward attendants and another study conducted by D'Souza p., et al (2020) shows no significant association between selected demographic variables and knowledge of body mechanics and body mechanics practices. ${ }^{[4,5]}$ In contrast to this study conducted by Jayakrishan K. (2016) conducted a descriptive study on Knowledge and practice among staff nurses regarding body mechanics at Odisha revealed that there was significant association between selected demographic variables \& knowledge score as well as significant association between selected demographic variables \& body mechanics practices. ${ }^{[8]}$

Some of the limitations of the study were that the present study was conducted only in selected wards of PGIMER Chandigarh and there was short duration of data collection period. Large sample size 
couldn't be collected due to restrictive movement in covid-19 areas. No interventions were included in the study to enhance knowledge of the hospital attendants regarding body mechanics and improve their body mechanics practices.

The Recommendations for further studies are Recommendations are they can be conducted at large scale and the every hospital in Chandigarh can be included into the study to make it stronger and generalize the findings. An educational package or intervention by RCT can be added enhance the knowledge and proper use of body mechanics techniques in further studies

\section{CONCLUSION}

The study findings reveal that most of the study subjects had poor knowledge and rest had good knowledge. In the present study subjects performance in general activities was average, for moving lifting and transferring heavy equipments was average, for transferring patients from stretcher to bed and vice versa was also average and for transferring patient from wheelchair to bed and vice versa was poor. There was no significant association of level of knowledge and socio-demographic profile. There was no significant association of musculoskeletal problems and body mechanics practices among hospital attendants.

\section{Acknowledgement: None}

\section{Conflict of Interest: None}

\section{Source of Funding: None}

\section{REFERENCES}

1. Lee H.J. The effects of tuina program on nurses with low back pain. Master's [Thesis].South Korea: Hanyang University Seoul; 2002.

2. Kaur L., Kaur M. Nursing Foundations. Jalandhar: Pee Vee Publication;2018.
3. Bamidele J., Adeoye O.,Oladele E., Ntaji.Occupational hazards exposure and their resultant effects on hospital attendants in health facilities of a local government area in South- Nigeria. Journal of Environmental and Occupational Science. 2014;3(2):97-102

4. D'Souza P., Frank R., Mathias A. Knowledge and uses of body mechanics among class IV workers. Int. J. Physiother.2020;7(6):264-268

5. Rawat A, Negi A, Rana M, Gusian M, Negi $\mathrm{N}$, Tomar $\mathrm{N}$ et al. Knowledge assessments on use of body mechanics and safety measures among ward attendants in selected hospitals, Dehradun, Uttarakhand.Int. J. Adv. Nur. Management.2017;5(4):288-292.

6. Afzal M, Gilani SA, Waqas A et al. Quantitative descriptive cross sectional study of knowledge and practices of body mechanics among nurses. Saudi J. Med. Pharm. Sci. 2017;3(6A):545-555

7. Vidya VP, Dennis S, D'souza, Machado V, Francis J, Gireesh GR et al. The knowledge and practice of body mechanics among staff nurses. International Journal of Nursing Science Practice and Research. 2014; 8(2):124-126.

8. Jayakrishan K. Knowledge and practice among staff nurses regarding body mechanics, Odishha. Int. J. Adv. Nur. Management. 2016;4(3):259-263.

9. Karahan A., Bayraktar N. Determination of the usage of body mechanics in clinical settings and the occurrence of low back pain in nurses International Journal of Nursing Study. 2004;41(1):67-75

10. Tariah H, Nafai S, Alajmi M, Almutairi F, Alanazi B. Work-related musculoskeletal disorders in nurses working in the Kingdom of Saudi Arabia. Work. 2020;65(2):421428.

How to cite this article: Priyanka, Kaur Ravneet, Sakshi et.al. Assess knowledge and use of body mechanics practices and its association with musculoskeletal problems among hospital attendants in selected wards of PGIMER, Chandigarh. Int J Health Sci Res. 2021; 11(9): 209-215. DOI: https://doi.org/10.52403/ijhsr. 20210933 